\title{
The Development of Medication Adherence Scale for Persons with Coronary Artery Disease (MAS-CAD): A Nursing Perspective
}

\author{
Kanoklekha SUWANNAPONG, Sureeporn THANASILP* and \\ Waraporn CHAIYAWAT
}

Faculty of Nursing, Chulalongkorn University, Bangkok 10330, Thailand

('Corresponding author's e-mail: s_thanasilp@hotmail.com)

Received: 31 May 2017, Revised: 22 January 2018, Accepted: 3 February 2018

\begin{abstract}
The purpose of this study was to develop a Medication Adherence Scale for Persons with Coronary Artery Disease (MAS-CAD) based on a nursing perspective. This study was guided by scale development procedures, which consisted of 7 steps: 1) clarifying and determining the concept, 2) generating an item pool, 3) determining the format for measurement, 4) reviewing the initial item pool by 7 professional experts, 5) conducting preliminary item pilot study with 30 Thais with CAD, 6) conducting field-testing for psychometric property testing among 457 Thais with CAD who attended heart clinics of 7 tertiary hospitals in Thailand, and 7) developing scoring and interpretation of the scale scores. Data were analyzed by using descriptive statistics, content validity index, Cronbach's alpha coefficient, confirmatory factor analysis by LISREL, and Pearson product moment correlation. The results showed that the MAS-CAD is a self-report instrument, comprised of 5 rating Likert-scale categorical format, composed of 25 items covering 4 constructs; proper knowledge of prescribed medication ( 7 items), storing medication appropriately (3 items), self-regulating medication administration correctly and continuously (11 items), and participating in the medication treatment plan (4 items). Psychometric property testing demonstrated satisfactory internal consistency with Cronbach's alpha coefficient of 0.81 , and test-retest reliability was acceptable $(\mathrm{r}=.62, \mathrm{p}<.01)$. Construct validity was supported by confirmatory factor analysis. In conclusion, the MAS-CAD is a reliable and valid instrument. Nurses can use this scale as a tool for assessing medication adherence for persons with CAD.
\end{abstract}

Keywords: Medication adherence, coronary artery disease, instrument development

\section{Introduction}

Coronary Artery Disease (CAD) is increasing in low and upper middle income countries including Thailand [1]. The goals for management of CAD are to control angina symptoms, treat underlying cause, and prevent myocardial infarction. All persons with CAD require long term medication treatment to prevent disease progression and recurrent cardiovascular events [2]. Therefore, medication adherence is important for these patients because it would lead to symptom control, decreased disease consequences and emergency room visit, hospital readmission and mortality [3].

Nurses are health care providers who are responsible and take an active role in assessment of medication adherence. Assessment is the first and most critical phase of the nursing process. The data gleaned from assessment is used to identify nursing diagnoses, collaborative problems, make referrals, make judgments about the effectiveness of nursing interventions, and to evaluate client care outcomes [4]. Based on the nursing perspective, medication adherence refers to the actions of the person with CAD related to taking medication as prescribed. These actions consist of proper knowledge of prescribed medication, storing medication appropriately, self-regulating medication administration correctly and 
http://wjst.wu.ac.th

continuously, and participating in the medication treatment plan [5]. Thus, an instrument used to measure medication adherence that has congruence with nursing practice is important.

Presently, there are various instruments that have been used to measure medication adherence such as the Morisky Medication Adherence Scale [6,7], Hill-Bone Compliance Scale [8], the Medication Adherence Scale (MAS) [9], the Medical Outcome Study (MOS) Specific Adherence Scale [10], and the Medication Adherence Rating Scale (MARS) [11]. Though these instruments are widely used to assess medication adherence by nurses, they are focused on determining adherence behaviors and barriers to non-medication adherence broadly [12]. However, they do not reflect an approach based on the nursing perspective that is specific for persons with CAD. Based on nursing perspective, nurses recognize the complexity and uniqueness of each person. They must have accurate information and be knowledgeable about existing conditions and patient circumstances, encouraging patients to change their behaviors. Therefore, this study was conducted from a nursing perspective aimed to develop a MAS-CAD to measure medication adherence for persons with CAD. This instrument will benefit nurses needing to assess medication adherence of persons with CAD. According to nurse deals with human response to actual or potential health problems and life processes while other providers focus on disease or medical condition. Correct data related to specific medication adherence will be a benefit nurses and their patients in order to establish appropriate interventions to improve medication adherence for persons with CAD. The instrument developed from this research can be considered reliable and valid for future researchers and practicing nurses.

\section{Materials and methods}

\section{Participants}

Participants were recruited from out-patient heart clinics of 7 tertiary hospitals from 5 geographic areas of Thailand including Ramathibodi hospital, Police hospital, Chonburi hospital, Thammasat hospital, Songkhlanakarin hospital, Sappasitthiprasong hospital, and Buddhachinaraj Phitsanulok hospital. Eligibility criteria for study inclusion were comprised of the following: consenting adult patients (18 years or older), able to communicate in Thai language, diagnosed with CAD by a physician as reported in their medical record at least 3 months preceding entry to the study, who were receiving medication treatment at least 3 month preceding entry to the study. Participants were excluded if they had unstable conditions or life threatening symptoms of CAD such as severe chest pain, acute myocardial infarction (MI). The participants were divided into 2 groups; 30 participants for preliminary item pilot testing, and 457 participants for psychometric properties testing. A multi-stage random sampling procedure was used to select participants into the study.

\section{Instrument development procedure}

The MAS-CAD was developed in Thai language based on an operational definition of the medication adherence. In this study, the operational definition of medication adherence for persons with CAD came from synthesizing the concept of medication adherence using a literature review and consensus of 17 experts through Delphi technique [5]. The expert panel consisted of nurses who met the following inclusion criteria: 1) advanced practice nurse (APN) certification, or publications on medication adherence for persons with cardiovascular disease, or teaching about medication adherence in persons with cardiovascular disease; 2) more than 3 years' clinical practice experience with persons with CAD; 3 ) currently employed in a clinical area; and 4) willing to participate in this study with sufficient time to participate in the Delphi process [5]. In this study, medication adherence refers to the actions of the person with $\mathrm{CAD}$ related to taking medication as prescribed. These actions consist of proper knowledge of prescribed medication, storing medication appropriately, self-regulating medication administration correctly and continuously, and participating in the medication treatment plan [5]. The first draft of the MAS-CAD was a self-reported questionnaire, 5-points Likert scale (untrue $=1$, quite untrue $=2$, neutral $=$ 3 quite true $=4$, and true $=5$ ) that consisted of 47 items covering the 4 attributes of the medication adherence concept, proper knowledge of prescribed medication (8 items), storing medication appropriately (9 items), self-regulating medication administration correctly and continuously (23 items), 
http://wjst.wu.ac.th

and participating in the medication treatment plan (7 items). Logical judgment by 7 professional experts who were knowledgeable in the content area was used to review the 47 items of the pool in the first draft. The item pool was revised and some items were deleted following comments and suggestions of the experts. The second draft of the scale emerged after content validity testing. The second draft of the scale was piloted for preliminary item testing with 30 persons with CAD, checking for readability, difficulty, and relevancy for persons with CAD's conditions. Preliminary item testing was comprised of informal methods. The final form of the MAS-CAD emerged based on comments and suggestions of the 30 pilot participants. The last step, the final draft of the MAS-CAD was administered in a large numbers of participants for psychometric property testing. The sample size determination was based on the criteria for set the sample size 10 subjects per item [13]. The researcher calculated the sample size since the second draft of the MAS which comprised of 43 items. Thus, a sample size of 430 was required. Ten percents of the total sample size was added to take into account drop outs to arrive at a true population value. Therefore, 473 participants were invited to participate in this study.

\section{Ethical considerations}

This study was approved by the Ethical Review Committee of the Faculty of Medicine, Ramathibodi hospital, Mahidol University (Approval No. 11-57-92), Police hospital (Approval No. 75/57), Chonburi hospital (Approval No. 54/2557), Thammasat University (Approval No. 153/2557), Faculty of Medicine, Prince of Songkla University (Approval No. 57-344-19-9), Sappasitthiprasong hospital (Approval No. 005/2558), and Buddhachinaraj Phitsanulok hospital (Approval No. 111/57). All participants gave written informed consent prior to participation in the study. Participants were informed that if they did not want to answer the questionnaires, they had the right to withdraw themselves from the study at any time. The standard treatment would be provided although they withdrew from the study. Their names were not presented in the data; rather a code number was used to ensure confidentiality.

\section{Data collection}

The patients were provided with explanations regarding the purpose of the study, study procedures, the content of the questionnaire, the participants' rights, and the potential benefits and risks of participation in the study. Following the provision of written informed consent by a patient, clinical data were collected from that patient's medical records. The researchers asked eligible participants to complete the MAS-CAD questionnaires. The questionnaires took about 15 - $20 \mathrm{~min}$ to complete. In this study, there were 457 participants completed the questionnaire.

\section{Statistical analysis}

Data were analyzed using descriptive statistics, content validity index (CVI), Cronbach's alpha coefficient, confirmatory factor analysis (CFA) by LISREL, and Pearson product moment correlation. Statistical significance was set at $\mathrm{p}<.05$.

\section{Results and discussion}

The final version of MAS-CAD is a self-reported questionnaire that consists of 25 items covering 4 constructs that include knowing about medication properly ( 7 items), storing medication appropriately (3 items), self-regulating in taking medication correctly and continuously (11 items), and participation in medication treatment plan (4 items) with a 5-choice Likert-scale format, scoring of each item from 1 to 5 (untrue $=1$, quite untrue $=2$, neutral $=3$ quite true $=4$, and true $=5$ ). Mean score was calculated for the scale. The scale score was interpreted as the level of medication adherence based on class interval (range/number of classes); high level (mean score $>3.67$ ), moderate level (mean score 2.34 - 3.67), and low level (mean score $<2.34$ ).

The present study shows that the MAS-CAD is a valid and reliable measure for assessing medication adherence for persons with CAD. Validity of the MAS-CAD was investigated by content validity and construct validity. In this study, content validity was obtained by computing CVI for both item level CVI (I-CVI) and scale level CVI (S-CVI/Ave). The results showed that the overall MAS-CAD 
http://wjst.wu.ac.th

had I-CVI score ranged from $0.86-1.00$, and S-CVI/Ave score was 0.99 . Content validity is the extent to which an instrument has an appropriate sample of items for the construct being measured [14]. The SCVI/Ave score indicates high scale content validity [14]. It means that the MAS-CAD has appropriate items for measuring medication adherence.

Confirmatory factor analysis (CFA) was used to test construct validity of the MAS-CAD. The results were presented in Table 1. The CFA result showed that the MAS-CAD model fits with the empirical data $\left(X^{2}=533.78, d f=244, \mathrm{p}=0.00, X^{2} / d f=2.19, \mathrm{GFI}=0.91\right.$, AGFI $=0.89, \mathrm{CFI}=0.94$, and RMSEA $=0.05)$. Construct validity is directly concerned with the theoretical relationship of a variable to other variables [13]. It informs that the instrument was really measuring, and adequately measuring the abstract concept of interest. The results also revealed that under investigation the factor structure in the modified model was a possible factor structure for the MAS-CAD construct. Regarding factor loading of the overall scale, results showed that all items were statically significant at $p=0.01$; standardized factor loading ranged from 0.22 - 0.85. Self-regulating medication administration correctly and continuously, participating in medication treatment plan, storing medication appropriately, and proper knowledge of prescribed medication dimension had standardized factor loading at $0.76,0.73,0.63$, and 0.55 , respectively. Square multiple correlations $\left(\mathrm{R}^{2}\right)$ of dimension ranged from $0.31-0.58$. Of 25 items, 5 items (item $8,11,12,19$, and 25) had standardized factor loading less than 0.3 . This indicates that these items should be considered for revision. Establishing construct validity is a complicated and time consuming process because it requires that the measuring instrument be used in a succession of different studies. Therefore, construct validity of the MAS-CAD needs further study to confirm.

Table 1 Standardized factor loading, estimated factor loading, and item reliability of the MAS-CAD (N = 457).

\begin{tabular}{|c|c|c|c|c|c|c|}
\hline No. & Dimension/Item & $\begin{array}{l}\text { Standardized } \\
\text { factor loading }\end{array}$ & $\begin{array}{c}\text { Estimated } \\
\text { factor loading }\end{array}$ & SE & t-value & $\mathbf{R}^{2}$ \\
\hline & $\begin{array}{l}\text { Proper knowledge of prescribed } \\
\text { medication }\end{array}$ & 0.55 & 0.59 & 0.08 & 7.58 & 0.31 \\
\hline 1. & $\begin{array}{l}\text { I know the benefits of the medicines } \\
\text { as prescribed by the doctor for me to } \\
\text { take }\end{array}$ & 0.58 & 0.71 & - & - & 0.33 \\
\hline 2. & $\begin{array}{l}\text { I know the negative side effect } \\
\text { symptoms that may occurred by the } \\
\text { prescribed medicines }\end{array}$ & 0.61 & 0.86 & 0.09 & 9.51 & 0.38 \\
\hline 3. & $\begin{array}{l}\text { I know the consequence if I do not } \\
\text { take the medicines prescribed by the } \\
\text { doctor }\end{array}$ & 0.59 & 0.77 & 0.08 & 9.63 & 0.35 \\
\hline 4. & $\begin{array}{l}\text { I know the correct way to take } \\
\text { medicines }\end{array}$ & 0.61 & 0.44 & 0.04 & 9.57 & 0.37 \\
\hline 5. & $\begin{array}{l}\text { I know the correct way to observe my } \\
\text { symptoms after taking a medicine }\end{array}$ & 0.77 & 0.90 & 0.09 & 10.27 & 0.60 \\
\hline 6. & $\begin{array}{l}\text { I know how to take appropriate action } \\
\text { if the negative side effects from the } \\
\text { medicine occures }\end{array}$ & 0.71 & 0.91 & 0.09 & 10.09 & 0.50 \\
\hline \multirow[t]{2}{*}{7.} & $\begin{array}{l}\text { I know the correct way to store } \\
\text { medicines }\end{array}$ & 0.43 & 0.32 & 0.04 & 7.61 & 0.18 \\
\hline & Storing medication appropriately & 0.63 & 0.48 & 0.17 & 2.88 & 0.39 \\
\hline 8. & I store medicines in a dry place & 0.22 & 0.13 & - & - & 0.05 \\
\hline 9. & I keep medicines in the completely & 0.37 & 0.34 & 0.13 & 2.60 & 0.14 \\
\hline
\end{tabular}




\begin{tabular}{|c|c|c|c|c|c|c|}
\hline No. & Dimension/Item & $\begin{array}{l}\text { Standardized } \\
\text { factor loading }\end{array}$ & $\begin{array}{c}\text { Estimated } \\
\text { factor loading }\end{array}$ & SE & t-value & $\mathbf{R}^{2}$ \\
\hline \multirow[t]{2}{*}{10.} & $\begin{array}{l}\text { I take medicines out of their foil packs } \\
\text { just when I want to take them }\end{array}$ & 0.38 & 0.65 & 0.25 & 2.61 & 0.14 \\
\hline & $\begin{array}{l}\text { Self-regulating medication } \\
\text { administration correctly and } \\
\text { continuously }\end{array}$ & 0.76 & 1.00 & 0.24 & 4.20 & 0.58 \\
\hline 11. & $\begin{array}{l}\text { I check an expiry date of medicines } \\
\text { before taking }\end{array}$ & 0.23 & 0.31 & - & - & 0.05 \\
\hline 12. & $\begin{array}{l}\text { I read carefully all the labels on } \\
\text { containers before taking medicines }\end{array}$ & 0.28 & 0.24 & 0.06 & 3.88 & 0.08 \\
\hline 13. & $\begin{array}{l}\text { I follow closely to all instructions } \\
\text { written all the labels on containers }\end{array}$ & 0.53 & 0.27 & 0.06 & 4.21 & 0.29 \\
\hline 14. & $\begin{array}{l}\text { I take medicines at the right time } \\
\text { prescribed by the doctor }\end{array}$ & 0.56 & 0.30 & 0.07 & 4.22 & 0.31 \\
\hline 15. & $\begin{array}{l}\text { I take all types of medicines } \\
\text { prescribed by the doctor }\end{array}$ & 0.61 & 0.23 & 0.05 & 4.29 & 0.37 \\
\hline 16. & $\begin{array}{l}\text { I take medicines the right dose } \\
\text { prescribed by the doctor }\end{array}$ & 0.53 & 0.15 & 0.04 & 4.06 & 0.28 \\
\hline 17. & $\begin{array}{l}\text { I do not either reduce or increase a } \\
\text { dose without consulting with the } \\
\text { doctor }\end{array}$ & 0.43 & 0.22 & 0.05 & 3.97 & 0.18 \\
\hline 18. & $\begin{array}{l}\text { I do continue taking the prescribed } \\
\text { medicine until the dosage is } \\
\text { completed }\end{array}$ & 0.56 & 0.23 & 0.05 & 4.24 & 0.31 \\
\hline 19. & $\begin{array}{l}\text { I ask the doctor, pharmacist, and nurse } \\
\text { about the way to take medicines } \\
\text { before starting to take those medicines }\end{array}$ & 0.27 & 0.33 & 0.09 & 3.80 & 0.07 \\
\hline 20. & $\begin{array}{l}\text { I continue to take medicines as } \\
\text { prescribed by the doctor even though I } \\
\text { feel better }\end{array}$ & 0.30 & 0.14 & 0.04 & 3.57 & 0.09 \\
\hline \multirow[t]{2}{*}{21.} & $\begin{array}{l}\text { I carry medicines with myself when I } \\
\text { have to go out }\end{array}$ & 0.39 & 0.25 & 0.06 & 3.91 & 0.15 \\
\hline & $\begin{array}{l}\text { Participating in the medication } \\
\text { treatment plan }\end{array}$ & 0.73 & 0.72 & 0.07 & 10.61 & 0.54 \\
\hline 22. & $\begin{array}{l}\text { I observe myself whether I am better } \\
\text { or not after taking medicines }\end{array}$ & 0.85 & 0.54 & - & - & 0.72 \\
\hline 23. & $\begin{array}{l}\text { I observe unpleasant symptoms that } \\
\text { might occur after taking medicines }\end{array}$ & 0.69 & 0.64 & 0.06 & 11.36 & 0.48 \\
\hline 24. & $\begin{array}{l}\text { I correctly inform the doctor about my } \\
\text { symptoms in order to adjust the way } \\
\text { to take medicines to suit my way of } \\
\text { life }\end{array}$ & 0.40 & 0.23 & 0.03 & 7.54 & 0.16 \\
\hline 25. & $\begin{array}{l}\text { I do taking part making the decision } \\
\text { with the doctor in choosing the } \\
\text { appropriate medicine for me }\end{array}$ & 0.28 & 0.49 & 0.09 & 5.47 & 0.08 \\
\hline
\end{tabular}


http://wjst.wu.ac.th

Reliability was tested by using internal consistency, and test-retest reliability. Internal consistency or homogeneity is another attribute of an instrument relates to the reliability with which the items within the scale reflect or measure the same concept [16]. The result showed that Cronbach's alpha of 25 items MAS-CAD was 0.81 . This result indicated an internal consistency of the overall scale higher than the usual acceptable value for a newly developed scale which usually set at 0.70 [17]. Stability is concerned with the same results being "obtained over repeated administration of instrument" [18]. The 2 sets of data are statistically compared. In this study, 2 weeks interval test-retest reliability was evaluated among 160 participants to determine the extent to which the 2 sets of scores were correlated. The result showed that Pearson product correlation of the MAS-CAD was $0.62(\mathrm{p}<.01)$. Regarding general criteria that $\mathrm{r}>0.50$ suggests that the instrument has a moderate relationship between 2 tests.

\section{Conclusions}

The MAS-CAD is a reliable and valid instrument. Nurses can use this scale as a tool for assessing medication adherence for persons with CAD. This scale is a simple questionnaire, and feasibility to use in adult patients. Moreover, this scale could be useful for medication adherence research and the development of appropriate interventions to improve medication adherence for persons with CAD.

\section{Acknowledgements}

This study was supported by grants from the $90^{\text {th }}$ Anniversary of Chulalongkorn University Fund (Ratchadaphiseksomphot Endowment Fund). The researchers would like to thank Associate Professor Dr. Dawn Liam Doutrich for editing and proofreading this article.

\section{References}

[1] S Kiatchoosakun, S Sutra and K Thepsuthammarat. Coronary artery disease in the Thai population: data from health situation analysis 2010. J. Med. Assoc. Thai 2012; 95, S149-S155.

[2] M Pflieger, BT Winslow, K Mills and IM Dauber. Medical Management of Stable Coronary Artery Disease. Am. Fam. Phys. 2011; 83, 819-26.

[3] A Bitton A, NK Choudhry, OS Matlin, K Swanton and WH Shrank. The impact of medication adherence on coronary artery disease costs and outcomes: A systematic review. Am. J. Med. 2013; 126, 357.e7-357.e27.

[4] JR Weber, JH Kelley and AD Sprengel. Lab Manual for Health Assessment in Nursing. Lippincott Williams \& Wilkins, 2014.

[5] K Suwannapong, S Thanasilp and W Chaiyawat. Medication adherence for persons with coronary artery disease: A Delphi study. J. Health Res. 2016; 30, 149-54.

[6] DE Morisky, LW Green and DM Levine. Concurrent and predictive validity of a self-reported measure of medication adherence. Med. Care 1986; 24, 67-74.

[7] DE Morisky, A Ang, M Krousel-Wood and HJ Ward. Predictive validity of a medication adherence measure in an outpatient setting. J. Clin. Hypertens. 2008; 10, 348-54.

[8] MT Kim, MN Hill, LR Bone and DM Levine. Development and testing of the Hill-Bone compliance to high blood pressure therapy scale. Prog. Cardiovasc. Nurs. 2000; 15, 90-6.

[9] JR Wu, M Chung, TA Lennie, LA Hall and DK Moser. Testing the psychometric properties of the medication adherence scale in patients with heart failure. Heart Lung 2008; 37, 334-43.

[10] RL Kravitz, RD Hays, CD Sherbourne, MR DiMatteo, WH Rogers, L Ordway and S Greenfield. Recall of recommendations and adherence to advice among patients with chronic medical conditions. Arch. Int. Med. 1993; 153, 1869-78.

[11] K Thompson, J Kulkarni and AA Sergejew. Reliability and validity of a new Medication Adherence Rating Scale (MARS) for the psychoses. Schizophr. Res. 2000; 42, 241-7.

[12] SM Lavsa, A Holzworth and NT Ansani. Selection of a validated scale for measuring medication adherence. J. Am. Pharm. Assoc. 2011; 51, 90-4. 
http://wjst.wu.ac.th

[13] RF Devellis. Scale Development: Theory and Applications. Sage Publications, California, USA, 2003.

[14] DF Polit and CT Beck. Essentials of Nursing Research: Appraising Evidence for Nursing Practice. $8^{\text {th }}$ ed. Wolters Kluwer Health, 2014.

[15] PA Dempsey and AP Dempsey. Using Nursing Research: Process, Critical Evaluation and Utilization. $5^{\text {th }}$ ed. Lippincott Williams and Wilkins, New York, 2000.

[16] GL Biondo-Wood and J Haber. Nursing Research: Methods and Critical Appraisal for Evidencebased Practice. Mosby Elsevier, Missouri, 2006.

[17] JC Nunnally and IH Bernstein. Psychometric Theory. $3^{\text {rd }}$ ed. McGraw-Hill, New York, 1994.

[18] JED Muth. Basic Statistics and Pharmaceutical Statistical Applications. ${ }^{\text {rd }}$ ed. Taylor \& Francis Group, 2014. 